\title{
Fertilizability and structural properties of boar spermatozoa prepared by Percoll gradient centrifugation
}

\author{
S. A. Grant ${ }^{1}$, S. E. Long ${ }^{1}$ and T. J. Parkinson ${ }^{2}$ \\ ${ }^{\mathrm{I}}$ Department of Animal Husbandry and ${ }^{2}$ Department of Veterinary Surgery, University of \\ Bristol, Langford House, Langford, Bristol BS18 7DU, UK
}

\begin{abstract}
Two techniques for the preparation of boar spermatozoa for in vitro fertilization were studied: a simple washing procedure and centrifugation on a discontinuous Percoll gradient. Their respective effects on motility of spermatozoa were analysed by computer-assisted sperm analysis. The Percoll density gradient technique selected spermatozoa with significantly $(P<0.0001)$ enhanced motility and movement characteristics. In vitro matured oocytes inseminated with spermatozoa prepared by Percoll gradient centrifugation had significantly $(P<0.0001)$ greater cleavage rates than did oocytes inseminated with washed spermatozoa. This increased penetration ability was not due to an increased proportion of acrosome-reacted spermatozoa. Transmission electron microscopy revealed no unique ultrastructural differences between the spermatozoa from either preparation. Spermatozoa prepared by Percoll gradient centrifugation are recommended for insemination and studies of porcine in vitro fertilization.
\end{abstract}

\section{Introduction}

Pig oocytes have been shown to mature, fertilize and develop in vitro (Iritani et al., 1978; Cheng, 1985; Cheng et al., 1986; Mattioli et al., 1989; reviewed by Hunter, 1990; Nagai et al., 1990; Yoshida et al., 1990; Wang et al., 1991). However, compared with human in vitro fertilization (IVF) programmes, consistent rates of normal fertilization and embryo cleavage remain disappointingly low. The unpredictability of boar spermatozoa undergoing an acrosome reaction in vitro concomitant with inadequate sperm motility contribute significantly to these poor results. Hence, a simple method to improve these factors may enhance fertilization and cleavage rates.

During the past decade, many human infertility research groups have reported that spermatozoa washed on a gradient of silica coated with polyvinylpyrolidine (Percoll: Sigma Chemical Co., Poole) demonstrate improved motility and in vitro fertilizing capacity (Gorus and Pipeleers, 1981; Arcidiacono et al., 1983; Forster et al., 1983; Kaneko et al., 1983, 1986, 1987; Lessley and Garner, 1983; Berger et al., 1985; Hyne et al., 1986; McClure et al., 1989; Nice et al., 1991). However, only a few workers have used Percoll to assist IVF in farm animals (Lessley and Garner, 1983; de Curtis et al., 1986; Berger and Horton, 1988; Berger and Parker, 1989; Mermillod et al., 1992) and most of these experiments specifically evaluated the motility of spermatozoa and the penetration of zona-free hamster oocytes. Consequently, no comparison has been made between the direct influence of sperm preparation technique and subsequent fertilization and development of matured oocytes in vitro.
This study was performed to determine whether boar spermatozoa washed on a Percoll gradient would enhance cleavage rates and embryo development in porcine oocytes matured in vitro. In addition, the morphological homogeneity of these spermatozoa was assessed.

\section{Materials and Methods}

\section{Culture and maturation of follicular oocytes}

Ovaries were collected from prepubertal gilts (Landrace $x$ Large White, body mass about $85 \mathrm{~kg}$ ) at slaughter and returned to the laboratory in saline $(0.9 \% \mathrm{NaCl}(\mathrm{w} / \mathrm{v}), 100$ iu benzyl penicillin $\mathrm{ml}^{-1}$ (Glaxo, Greenford)) at $37^{\circ} \mathrm{C}$ within $1 \mathrm{~h}$. Follicles, $2-5 \mathrm{~mm}$ in diameter, were aspirated with a $1 \mathrm{ml}$ syringe equipped with a 25 gauge needle, and the follicular fluid was diluted with TCM 199 (containing Earle's salts, $25 \mathrm{mmol}$ Hepes $\mathrm{I}^{-1}$ and L-glutamic acid (Gibco, Life Technologies Ltd, Paisley)). Only oocytes possessing a compact cumulus mass and evenly granulated cytoplasm were selected for the experiments. The compact oocyte complexes were cultured at $39^{\circ} \mathrm{C}$ under humidified $5 \% \mathrm{CO}_{2}$ in maturation medium TCM 199 containing $10 \%(\mathrm{v} / \mathrm{v})$ heat-inactivated fetal calf serum (FCS: Imperial, Andover), $75 \mathrm{iu}$ hCG $\mathrm{ml}^{-1}$ (Chorulon: Intervet, Cambridge), $50 \mathrm{iu}$ Penicillin $\mathrm{ml}^{-1}$ (Gibco), $50 \mu \mathrm{g}$ Streptomycin $\mathrm{ml}^{-1}$ (Gibco) and $\mathrm{I} \mu \mathrm{g}$ oestradiol ml ${ }^{-1}$ (Sigma Chemical Co., Poole). After incubation for 28-34 h, maturation of cumulus-oocyte complexes was evaluated under a stereomicroscope and those complexes with an expanded cumulus mass were selected for IVF. 


\section{Preparation of a discontinuous Percoll column}

Nine parts of Percoll (Sigma Chemical Co.) were diluted $(\mathrm{v} / \mathrm{v})$ with one part of concentrated $(\times 10)$ modified Tyrode's solution originally designated TALP (Tyrode-albumin-lactatepyruvate, Bavister and Yanagimachi, 1977; Bavister, 1989) to make isotonic Percoll. TALP medium $(x 1)$ supplemented with $2 \mathrm{mg} \mathrm{BSA} \mathrm{ml} \mathrm{ml}^{-1}$ (Fraction V, Globulin Free, Sigma Chemical Co.), $0.25 \mathrm{mmol}$ sodium pyruvate $\mathrm{l}^{-1}$ (Gibco Life Technologies Ltd), 50 iu penicillin $\mathrm{ml}^{-1}$ and $50 \mu \mathrm{g}$ Streptomycin $\mathrm{ml}^{-1}$ (TALP-BSA) was then mixed with isotonic Percoll in appropriate proportions to make $40 \%$ and $90 \%$ isotonic Percoll. A discontinuous Percoll gradient was prepared by carefully layering $4 \mathrm{ml}$ of $90 \%$ isotonic Percoll beneath $4 \mathrm{ml}$ of $40 \%$ isotonic Percoll in a sterile $15 \mathrm{ml}$ centrifuge tube (Falcon, Becton Dickinson UK Ltd, Oxford) such that the interface between the layers was visible.

\section{Preparation and incubation of spermatozoa}

Boar semen, commercially prepared for artificial insemination (JSR Healthbred, Selby), was delivered to the laboratory within $24 \mathrm{~h}$ of collection. Throughout the experiment, semen from the same two boars was used to minimize inter-boar variation. Two methods of preparing the spermatozoa were evaluated.

Method 1. To remove the commercial extender and concentrate spermatozoa, spermatozoa were initially washed twice in TALP-BSA by centrifugation at $250 \mathrm{~g}$ for $4 \mathrm{~min}$. The final pellet was resuspended in approximately $1 \mathrm{ml}$ of medium to give a final concentration of $3 \times 10^{9}$ spermatozoa $\mathrm{ml}^{-1}$. To maintain the $\mathrm{pH}$, the sperm suspension was gently gassed with $5 \% \mathrm{CO}_{2}$, then incubated at $37^{\circ} \mathrm{C}$ for $5 \mathrm{~h}$ in a tightly capped test-tube (washed spermatozoa).

Method 2. Spermatozoa were initially washed as described above. The final pellet was resuspended to about $1.5 \mathrm{ml}$, which was layered on top of a 40:90 discontinuous Percoll gradient and centrifuged at $300 \mathrm{~g}$ for $35 \mathrm{~min}$. The resultant pellet was carefully removed from the bottom of the column and washed twice more in TALP-BSA. After aspiration of the final supernatant, the pellet was resuspended to a concentration of $3 \times 10^{9}$ spermatozoa $\mathrm{ml}^{-1}$, the tube was gassed and incubated at $37^{\circ} \mathrm{C}$ for $5 \mathrm{~h}$ (spermatozoa prepared by Percoll gradient centrifugation).

\section{In vitro fertilization, embryo culture and examination of oocytes}

Mature oocytes $(15-20)$ were transferred to a droplet $(40 \mu \mathrm{l})$ of TALP-BSA medium under paraffin oil. The IVF dishes (35 mm, Falcon) were prepared and incubated under humidified $5 \% \mathrm{CO}_{2}$ at $39^{\circ} \mathrm{C}$ sufficiently in advance of the experiment to allow equilibration of the oil and the culture medium droplets. A portion of the appropriate preincubated sperm suspension was introduced into the TALP-BSA droplets to give a final concentration of between $5 \times 10^{5}$ and $1 \times 10^{6}$ spermatozoa $\mathrm{ml}^{-1}$. The rate of polyspermic fertilization was examined by randomly removing some oocytes $12-15 \mathrm{~h}$ after insemination, and fixing them with acetic-alcohol (methanol:acetic acid, 3:1 $\mathrm{v}: \mathrm{v})$ for at least $24 \mathrm{~h}$ and staining with $1 \%$ aqueous aceto-orcein.
The remaining oocytes were cultured for a further $65 \mathrm{~h}$ to examine their developmental capacity. The assessment of cleavage was performed at intervals of $24 \mathrm{~h}$.

\section{Analysis of sperm motility}

Sperm motility parameters were measured with a Hamilton Thorne Motility Analyser Version 7 (HTM; Hamilton Thorne Res. Inc, Danvers). A $20 \mu \mathrm{l}$ sample of each sperm suspension was placed in a disposable Micro-cell counting chamber (Microcell, Cyto-Fluidics, Silver-Spring, MD) and the sample analysed immediately as delays in the procedure enable the spermatozoa to agglutinate or adhere to the glass surface. Motility was measured using the internal microscope of the analyser, with the parameter settings adjusted as follows from the manufacturer's recommended values for analysing bovine spermatozoa: temperature, $37^{\circ} \mathrm{C}$; diluent:sample, 0:1 (v:v); chamber, Micro-cell $(20 \mu \mathrm{m})$; image type, phase contrast; field selection, select; calculate ALH, yes; morphology, live; beat frequency, yes; automatic sort, no; allow static override, no; main gates, frames, 20; frame rate, $25 \mathrm{~s}^{-1}$; minimum contrast, 4; minimum size, 3 ; $\mathrm{LO} / \mathrm{HI}$ size gates, $0.5,1.5 ; \mathrm{LO} / \mathrm{HI}$ intensity gates, 0.5, 1.5; non-motile head size, 10; non-motile intensity, 190; medium mean path velocity (VAP) value, 25; low VAP value, 10; low cells motile, no; threshold STR (straight track ratio), 75. Preliminary trials using the play-back facility of the machine confirmed that the size and contrast settings enabled the computer to differentiate accurately between motile and immotile spermatozoa.

The variables of sperm movement characteristics evaluated in this study included mean path velocity (VAP; $\mu \mathrm{m} \mathrm{s}^{-1}$ ), percentage of motile spermatozoa (VAP $>10 \mu \mathrm{m} \mathrm{s}^{-1}$ ), percentage of spermatozoa with rapid motility (VAP $>25 \mu \mathrm{m}$ $\mathrm{s}^{-1}$ ), progressive velocity (VSL; $\mu \mathrm{m} \mathrm{s}^{-1}$ ), track velocity (VCL; $\mu \mathrm{m} \mathrm{s}^{-1}$ ), amplitude of lateral head displacement (LHD; $\mu \mathrm{m}$ ) and beat cross frequency $(\mathrm{BCF} ; \mathrm{Hz})$.

\section{Determination of the acrosomal status of spermatozoa}

After incubation for $0,1,3$ and $5 \mathrm{~h}$, aliquots of spermatozoa prepared by both methods were stained with Naphthol Yellow and Erythrosin B and assayed for the presence or loss of acrosomes according to the method of Bryan and Akruk (1977). A minimum of 800 cells were analysed from each aliquot.

\section{Transmission electron microscopy}

After incubation for $0,1,3$ and $5 \mathrm{~h}$, aliquots of spermatozoa prepared by Percoll gradient centrifugation and washed spermatozoa were fixed in $2.5 \%$ gluteraldehyde in $0.1 \mathrm{~mol}$ sodium cacodylate buffer $1^{-1}$ at $4^{\circ} \mathrm{C}$ for a minimum of $4 \mathrm{~h}$. Spermatozoa were then postfixed in $2 \%$ osmium tetroxide in buffer $\left(0.2 \mathrm{~mol} \mathrm{I}^{-1}\right)$ for $1 \mathrm{~h}$, rinsed twice in buffer and serially dehydrated in $70 \%, 90 \%$ and $100 \%$ ethanol. Samples were processed with propylene oxide and propylene:epoxy resin $(50: 50 \mathrm{v}: \mathrm{v})$, embedded and polymerized at $60^{\circ} \mathrm{C}$ for $48 \mathrm{~h}$. Thin sections of the spermatozoa were then stained with saturated uranyl acetate in $50 \%$ methanol for $20 \mathrm{~min}$ followed by Reynold's lead citrate for $5 \mathrm{~min}$, and viewed using a Philips 300 transmission electron microscope. 

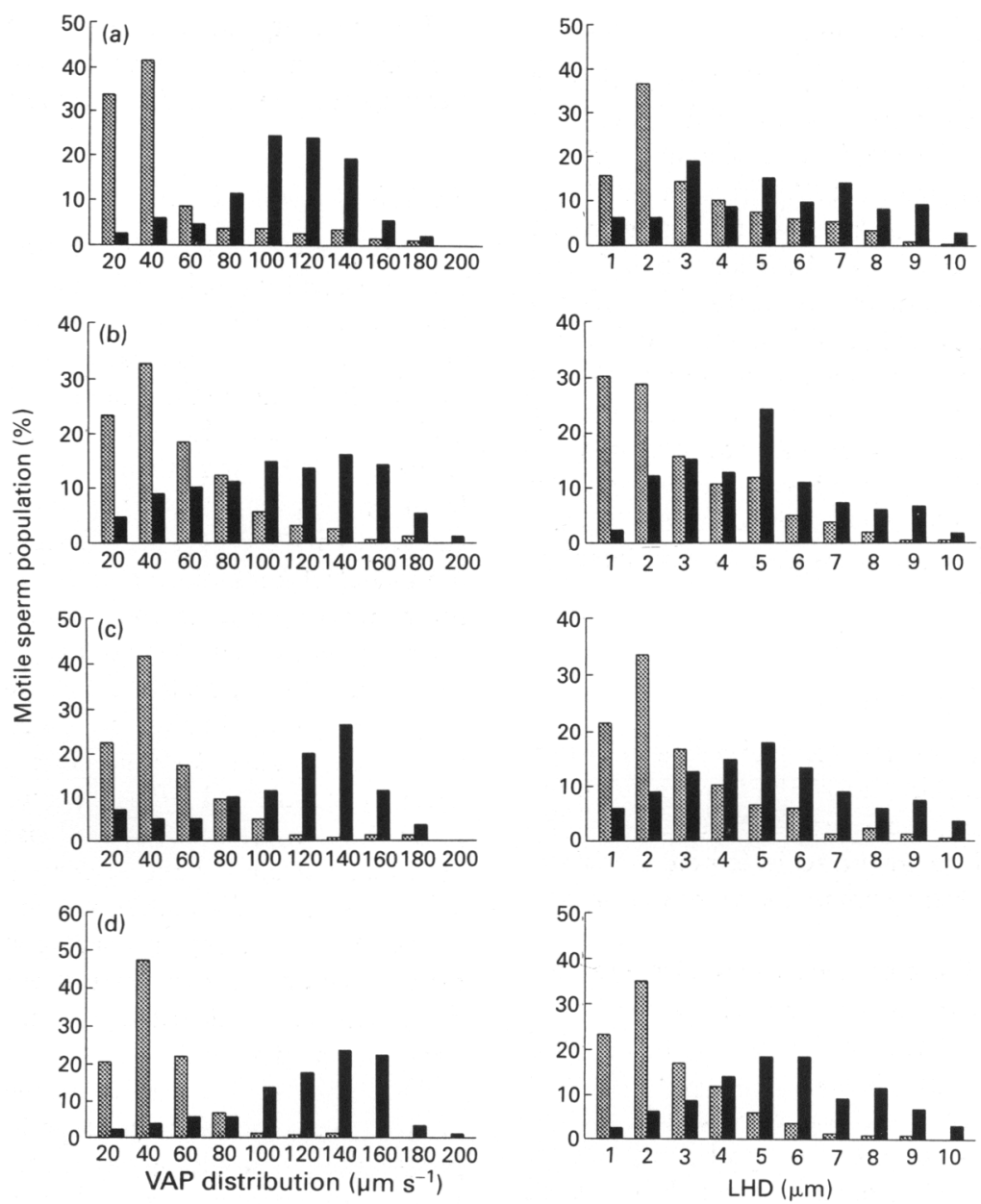

Upper boundary of range

Fig. 1. The distribution of progressive velocity (VAP; $\mu \mathrm{m} \mathrm{s}^{-1}$ ) and lateral head displacement (LHD; $\mu \mathrm{m}$ ) as percentages of the motile sperm population prepared by washing (圈) or Percoll centrifugation (a) after (a) 0, (b) 1, (c) 3 and (d) $5 \mathrm{~h}$ incubation.

\section{Statistical analysis}

Significant relationships between sperm motility characteristics within sperm treatments were determined by subjecting the relevant data to linear correlation analysis. Significant differences of individual variables between treatments were tested by standard analysis of variance and least significant differences. Differences between polyspermic fertilization and cleavage rates were tested according to the $\chi^{2}$ method.

\section{Results}

\section{Sperm motility}

The distribution of VAP and LHD for both preparations are shown (Fig. 1). Results from spermatozoa prepared on the Percoll gradient were skewed towards a high proportion of fast-moving spermatozoa with a large LHD. The Percoll technique significantly enhanced $(P<0.0001)$ all velocity parameters measured (Table 1). By contrast, the distribution of the washed spermatozoa was markedly skewed towards slower speeds with a mode of $20-40 \mu \mathrm{m} \mathrm{s}^{-1}$ and a correspondingly smaller lateral head displacement.

Characteristics of sperm velocity (i.e. VAP, VSL and VCL) were strongly correlated with each other and with LHD in both preparations. There was a negative correlation between $\mathrm{BCF}$ and all other measurements.

Incubation time had a minimal effect with a small but significant $(P<0.05)$ decrease in percentage of motile spermatozoa in both preparations and in percentage of rapidly motile Percoll-prepared spermatozoa after $\mathrm{I}$ h. Velocity parameters increased and reached maximum values after $\mathrm{I}$ and $3 \mathrm{~h}$ for the washed spermatozoa and Percoll-gradient-prepared spermatozoa, respectively.

\section{Acrosomal status of spermatozoa}

The number of spermatozoa without acrosomes increased significantly during incubation of each preparation (Table 2). 
Table 1. Mean ( \pm SEM) of boar spermatozoa motility and movement characteristics assessed by the Hamilton Thorne Motility Analyser for Percoll-prepared and washed spermatozoa

\begin{tabular}{|c|c|c|c|c|c|}
\hline \multirow[b]{2}{*}{ Sperm parameter } & \multirow[b]{2}{*}{ Sperm preparation } & \multicolumn{4}{|c|}{ Incubation time (h) } \\
\hline & & 0 & 1 & 3 & 5 \\
\hline Motile spermatozoa (\%) & $\begin{array}{l}\text { Percoll } \\
\text { Wash }\end{array}$ & $\begin{array}{l}80.0 \pm 3.7^{\mathrm{e}} \\
77.5 \pm 3.2\end{array}$ & $\begin{array}{l}65.1 \pm 4.4^{8} \\
61.9 \pm 8.4\end{array}$ & $\begin{array}{l}70.2 \pm 3.6 \\
75.0 \pm 5.7\end{array}$ & $\begin{array}{l}67.4 \pm 6.3 \\
75.5 \pm 3.6\end{array}$ \\
\hline Rapid motility (\%) & $\begin{array}{l}\text { Percoll } \\
\text { Wash }\end{array}$ & $\begin{array}{l}77.7 \pm 3.5^{\text {ae }} \\
39.5 \pm 4.5^{c}\end{array}$ & $\begin{array}{l}61.2 \pm 4.8^{\mathrm{ag}} \\
40.4 \pm 8.0^{\mathrm{d}}\end{array}$ & $\begin{array}{l}63.9 \pm 4.3^{\mathrm{a}} \\
46.6 \pm 4.8^{\mathrm{d}}\end{array}$ & $\begin{array}{l}64.6 \pm 6.4 \\
47.4 \pm 7.2\end{array}$ \\
\hline $\begin{array}{l}\text { Mean path velocity } \\
\left(\mathrm{VAP}, \mu \mathrm{m} \mathrm{s}^{-1}\right)\end{array}$ & $\begin{array}{l}\text { Percoll } \\
\text { Wash }\end{array}$ & $\begin{array}{l}95.8 \pm 4.6^{\text {ae }} \\
38.5 \pm 2.0^{\mathrm{b}}\end{array}$ & $\begin{array}{l}98.8 \pm 4.7^{\mathrm{a}} \\
44.0 \pm 2.1^{\mathrm{b}}\end{array}$ & $\begin{array}{r}113.4 \pm 8.8^{\mathrm{ag}} \\
40.5 \pm 1.9^{\mathrm{b}}\end{array}$ & $\begin{array}{r}111.7 \pm 4.9^{\mathrm{a}} \\
35.3 \pm 3.5^{\mathrm{b}}\end{array}$ \\
\hline $\begin{array}{l}\text { Progressive velocity } \\
\text { (VSL, } \mu \mathrm{m} \mathrm{s}^{-1} \text { ) }\end{array}$ & $\begin{array}{l}\text { Percoll } \\
\text { Wash }\end{array}$ & $\begin{array}{l}83.3 \pm 5.7^{\mathrm{a}} \\
27.5 \pm 0.6^{\mathrm{b}}\end{array}$ & $\begin{array}{l}89.5 \pm 4.5^{\mathrm{a}} \\
37.4 \pm 1.2^{\mathrm{b}}\end{array}$ & $\begin{array}{r}105.3 \pm 9.2^{\mathrm{a}} \\
33.8 \pm 1.7^{\mathrm{b}}\end{array}$ & $\begin{array}{r}104.3 \pm 4.8^{\mathrm{a}} \\
27.6 \pm 2.0^{\mathrm{b}}\end{array}$ \\
\hline $\begin{array}{l}\text { Track velocity } \\
\left(\mathrm{VCL}, \mu \mathrm{m} \mathrm{s}^{-1}\right)\end{array}$ & $\begin{array}{l}\text { Percoll } \\
\text { Wash }\end{array}$ & $\begin{array}{r}109.3 \pm 4.5^{\mathrm{a}} \\
43.6 \pm 2.4^{\mathrm{b}}\end{array}$ & $\begin{array}{c}107.0 \pm 4.4^{\mathrm{ac}} \\
47.6 \pm 3.3^{\mathrm{b}}\end{array}$ & $\begin{array}{c}122.7 \pm 7.7^{\mathrm{ag}} \\
43.8 \pm 2.3^{\mathrm{b}}\end{array}$ & $\begin{array}{r}121.6 \pm 5.0^{\mathrm{ag}} \\
38.4 \pm 3.7^{\mathrm{b}}\end{array}$ \\
\hline $\begin{array}{l}\text { Beat cross frequency } \\
\text { (BCF, Hz) }\end{array}$ & $\begin{array}{l}\text { Percoll } \\
\text { Wash }\end{array}$ & $\begin{array}{l}7.7 \pm 0.9^{e} \\
9.5 \pm 0.9\end{array}$ & $\begin{array}{c}10.7 \pm 0.7^{f} \\
9.9 \pm 0.8\end{array}$ & $\begin{aligned} 10.5 & \pm 0.6^{\mathrm{f}} \\
9.7 & \pm 0.3\end{aligned}$ & $\begin{array}{r}11.0 \pm 0.8^{\mathrm{f}} \\
9.3 \pm 0.5\end{array}$ \\
\hline
\end{tabular}

a.b,c,d Within columns, values with different superscripts are significantly different (a versus $b, P<0.0001$; a versus $c, P<0.001$; a versus $d, P<0.05$ ).

e.f, Within rows, values with different superscripts are significantly different (e versus $f, P<0.01$; e versus $g, P<0.05$ ).

Table 2. Percentage of spermatozoa without acrosomes after $0,1,3$ and $5 \mathrm{~h}$ incubation for Percoll and washed sperm preparations

\begin{tabular}{lcccc}
\hline & \multicolumn{4}{c}{ Incubation time (h) } \\
\cline { 2 - 5 } Sperm preparation & 0 & 1 & 3 & 5 \\
\hline Percoll & $\ldots .8^{\mathrm{c}}$ & $21.2^{\mathrm{ad}}$ & $24.1^{\mathrm{d}}$ & $24.7^{\mathrm{d}}$ \\
Wash & $3.4^{\mathrm{ce}}$ & $8.7^{\mathrm{bct}}$ & $22.5^{\mathrm{d}}$ & $23.5^{\mathrm{d}}$
\end{tabular}

a, Within columns, values with different superscripts are significantly different (a versus $b, P<0.0001$ ).

c.d.e.fWithin rows, values with different superscripts are significantly different $(c$ versus $\mathrm{d}, P<0.0001$; e versus $\mathrm{f}, P<0.001$ ).

After $I \mathrm{~h}$, a significantly greater $(P<0.0001)$ percentage of Percoll gradient prepared spermatozoa had no acrosomes, but after $5 \mathrm{~h}$ (i.e. usual time of insemination), there was no significant difference between the two preparations.

\section{Polyspermic fertilization rate}

A significantly greater $(P<0.001)$ proportion of oocytes inseminated with Percoll-gradient-prepared spermatozoa $\{37.5 \%)$ were polyspermic compared with those inseminated with washed spermatozoa $(4.5 \%)$.

\section{Embryo cleavage rates}

Table 3 shows the comparative cleavage rates. The chi-squared test demonstrated a significantly $(P<0.0001)$ improved cleavage rate by the oocytes inseminated with
Percoll-gradient-prepared spermatozoa compared with the washed spermatozoa preparation.

\section{Electron microscopy}

An example of the transmission electron micrographs developed from the sperm preparations after $5 \mathrm{~h}$ incubation is shown (Fig. 2). Although no unique ultrastructural differences could be detected between the two preparations, the washed spermatozoa contained a notable amount of dead or damaged spermatozoa and amorphous material.

\section{Discussion}

The study reported here clearly demonstrates that, compared with conventional washing techniques, boar spermatozoa exhibit an enhanced function after a combination of washing and Percoll gradient centrifugation. These results support the extensive data from human studies (Akerlof et al., 1987; Gellert-Mortimer et al., 1988; Guerin et al., 1989; McClure et al., 1989; Englert et al., 1992) and confirm the observations that the penetration of hamster oocytes is significantly greater by boar spermatozoa washed on a Percoll gradient compared with those prepared by dilution (Berger and Horton, 1988) or swim-up (Berger and Parker, 1989).

Although it was not possible to distinguish the precise aspect of sperm function that was enhanced by the Percoll technique, the computer-generated data clearly demonstrated a significant increase in motility and head movement characteristics after Percoll centrifugation compared with after simple washing. It has been suggested that increased sperm motility plays an important role in zona penetration, by thrusting the acrosome through the zona using released acrosomal enzymes (Fraser, 1984). Hence, the faster propulsion of Percoll-prepared 
Table 3. Cleavage rate and stage of embryonic development achieved by oocytes inseminated with Percoll-prepared or washed spermatozoa

\begin{tabular}{lcccccc}
\hline & & \multicolumn{5}{c}{ Embryo stage } \\
\cline { 3 - 7 } Sperm preparation & Cleavage rate & 2 -3-cell & $4-5$-cell & $6-7$-cell & 8 -10-cell & $11-12$-cell \\
\hline Percoll & $117 / 194^{\mathrm{a}}$ & 4 & $34^{\mathrm{a}}$ & $29^{\mathrm{a}}$ & $32^{\mathrm{a}}$ & $18^{\mathrm{a}}$ \\
\multirow{3}{*}{ Wash } & $(60.3 \%)$ & $(2.0 \%)$ & $(17.5 \%)$ & $(14.9 \%)$ & $(16.5 \%)$ & $(9.3 \%)$ \\
& $25 / 215^{\mathrm{b}}$ & 3 & $10^{\mathrm{b}}$ & $6^{\mathrm{b}}$ & $4^{\mathrm{b}}$ & $2^{\mathrm{b}}$ \\
& $(11.6 \%)$ & $(1.3 \%)$ & $(4.7 \%)$ & $(2.8 \%)$ & $(1.7 \%)$ & $(0.9 \%)$ \\
\hline
\end{tabular}

a,b Within columns, values with different superscripts are significantly different (a versus $b, P<0.0001$ ).
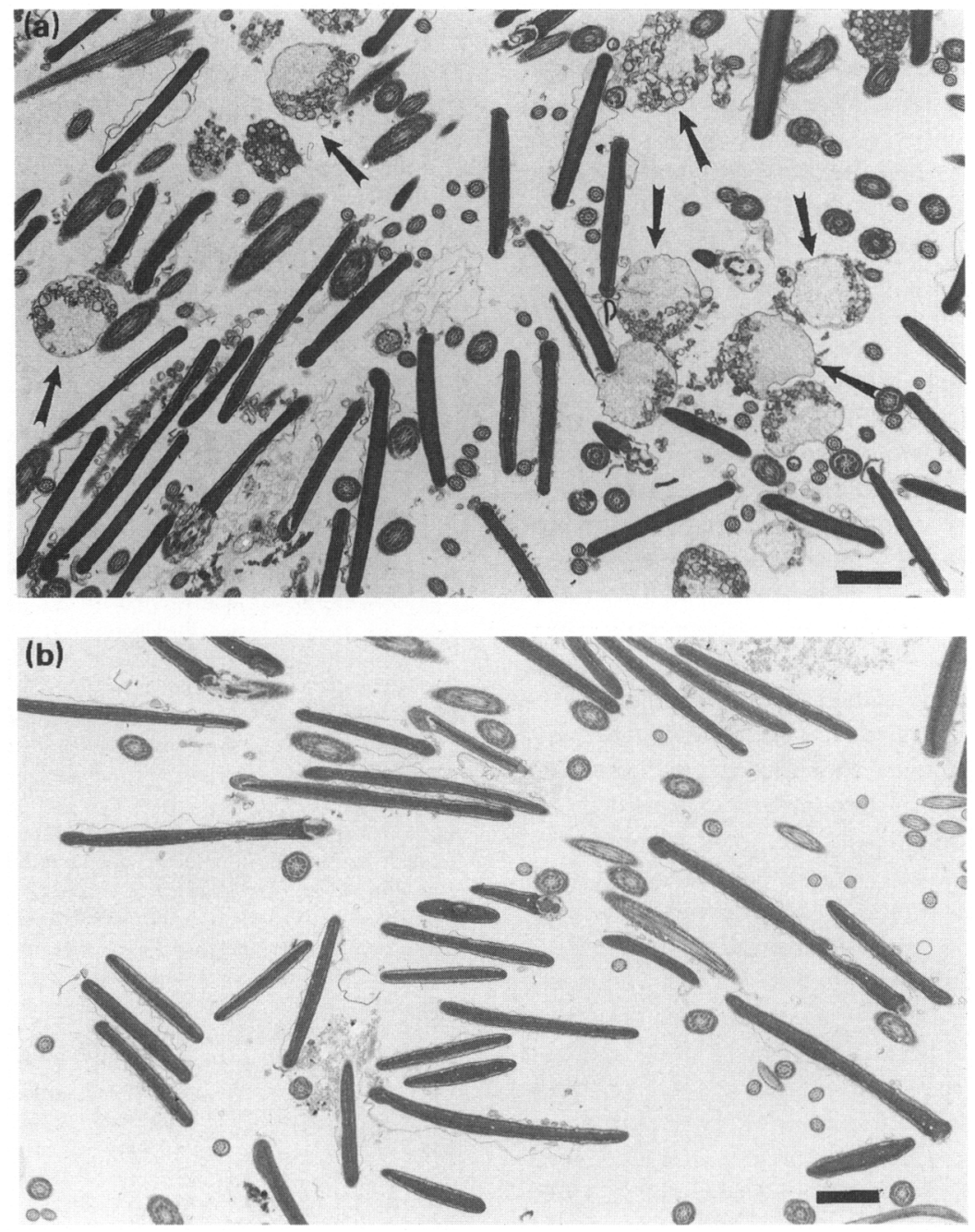

Fig. 2. Electron micrographs of (a) washed and (b) Percoll-prepared sperm preparations after incubation for $5 \mathrm{~h}$ at $37^{\circ} \mathrm{C}$. Note the large amount of debris in the washed sample. Arrows indicate degenerating dead spermatozoa and amorphous material. Scale bar represents $1.7 \mu \mathrm{m}$.

spermatozoa, in association with vigorous head movement, may contribute to improved fertilizing capacity. The tendency for beat cross frequency to decrease linearly with increasing velocity suggests that this parameter is not crucial for optimum fertilization.
Although the rate of spontaneous acrosome reactions was similar with both techniques after $5 \mathrm{~h}$ incubation (i.e. at an equivalent time to insemination), the initial rate was much higher for the Percoll-prepared spermatozoa than for the washed spermatozoa. However, it seems unlikely that this 
difference directly influenced the observed fertilization and cleavage rate since evidence from human studies indicated that an accelerated rate of spontaneous acrosome reactions does not result in a concomitant increase in oocyte penetration (Fenichel et al., 1991).

In contrast to studies in humans (Tanphaichitr et al., 1988), no unique ultrastructural differences were detected between the spermatozoa in each preparation. However, the electron micrographs confirmed that the Percoll procedure yielded pure fractions of spermatozoa, whereas the washing technique produced cell pellets that contained a heterogeneous population of spermatozoa in addition to amorphous material and seminal plasma. Seminal plasma components have previously been shown to compromise the motility (Jeng et al., 1993) and capacitation process (Chang, 1957) of spermatozoa. Furthermore, evidence from human studies suggests that the presence of non-functional gametes within these unfractionated sperm suspensions impairs the fertilizing ability of normal spermatozoa, by the generation of an excessive production of reactive oxygen species that irreversibly damage membrane function (Aitken, 1988; Aitken and Clarkson, 1988) and influence sperm movement characteristics (Aitken et al., 1993). The significantly reduced motility and fertilizing ability of the washed spermatozoa certainly lends support to these observations.

Although many porcine IVF experiments have reported high oocyte penetration rates (Nagai et al., 1983; Cheng et al., 1986; Yoshida, 1987; Mattioli et al., 1989; Wang et al., 1991), few studies have cultured oocytes matured and fertilized in vitro beyond $44 \mathrm{~h}$ (Rath, 1992; Wu et al., 1992; Zhu et al., 1992). The embryo cleavage rate achieved with the Percoll spermatozoa in this experiment was notably better than that achieved in these studies and supports the proposal derived from human studies (Le Lannou and Blanchard, 1988; Van der Zwalmen et al., 1991) that the selection of highly motile, morphologically normal spermatozoa from the gradient leads to an improvement of the quality of the embryos fertilized in vitro and ultimately embryonic development. Human clinical pregnancy and birth rates were almost doubled when spermatozoa were centrifuged on a Percoll gradient compared with standard migration techniques (Guerin et al., 1989). Additional embryo transfer experiments are required to extend these observations to pigs.

The differing rate of polyspermic fertilization recorded for each sperm preparation further emphasized the enhanced penetrating ability of the Percoll-gradient-prepared spermatozoa, and confirmed that the poor development of the oocytes inseminated with washed spermatozoa was not due to excessive polyspermy. Although the incidence of polyspermy was comparable with previous studies (Nagai et al., 1983; Cheng, 1985; Yoshida, 1987; Mattioli et al., 1989; Kikuchi et al., 1993), this level is still unacceptably high. Since one of the major factors influencing polyspermy is the number of capacitated spermatozoa at the site of fertilization (Hunter, 1973, 1976), further research is required to optimise the 'Percoll' in vitro fertilization system without suppressing the present high rate of fertilization.

The computer-assisted semen analysis enabled a rapid assessment of each sample and an accurate evaluation of the sperm motility parameters. This technique alleviated the problem of head to head agglutination that routinely occurs during incubation (Berger and Horton, 1988) and which rapidly form on a haemocytometer during manual analysis. Evidence from porcine (Tuli et al., 1992), bovine (Anzar et al., 1991; Tuli et al., 1992) and ovine (Suttiyotin and Thwaites, 1992) studies support the efficacy of the HTM analyser for assessing animal spermatozoa but emphasize the importance of determining the correct computer program options so that accurate cell concentrations and motility measurements are obtained.

The results of this study confirm the findings of many previous reports (Forster et al., 1983; Berger et al., 1985; McClure et al., 1989; Chan and Tucker, 1992) that separation of spermatozoa from seminal plasma by centrifugal washing in culture medium on a two-step Percoll gradient is a convenient and efficient way to prepare a population of fertile spermatozoa, but the reasons for its superiority over other separation methods remain unknown. Since the majority of porcine IVF studies have routinely used simple spermatozoa washing and incubation procedures, we propose that fertilization and cleavage rates could be markedly improved by a simple modification of spermatozoa preparation techniques.

The authors thank A. Skews for the excellent preparation of the electron micrographs, JSR Healthbred for the generous donation of boar semen and the Department of Obstetrics and Gynaecology, University of Bristol, for allowing us to use their Hamilton Thorne Motility Analyser. This research was supported by a grant from the Ministry of Agriculture, Fisheries and Food.

\section{References}

Aitken RJ (1988) Assessment of sperm function for IVF Human Reproduction 3 $89-95$

Aitken RJ and Clarkson JS (1988) Significance of reactive oxygen species and anti-oxidants in defining the efficacy of sperm preparation techniques Journal of Andrology 9 367-376

Aitken RJ, Harkiss D and Buckingham D (1993) Relationship between ironcatalysed lipid peroxidation potential and human sperm function Journal of Reproduction and Fertility 98 257-265

Akerlof E, Fredricson B, Gustafsson O, Lundin A, Lunell NO, Nylund L, Rosenberg L and Pousette A (1987) Comparison between a swim-up and a Percoll gradient for the separation of human spermatozoa International Joumal of Andrology 10 663-669

Anzar M, Hassan MM, Graham EF, Deyo RCM and Singh G (1991) Efficiency of the Hamilton Thom Motility Analyser (HTM-2030) for the evaluation of bovine semen Theriogenology 36 307-317

Arcidiacono A, Walt H, Campana A and Balerna M (1983) The use of Percoll gradients for the preparation of subpopulations of human spermatozoa International journal of Andrology 6 433-445

Bavister BD (1989) A consistently successful procedure for in vitro fertilisation of golden hamster eggs Gamete Research 23 139-158

Bavister BD and Yanagamachi R (1977) The effects of sperm extracts and energy sources on the motility and acrosome reaction of hamster spermatozoa in vitro Biology of Reproduction 28 235-247

Berger T and Horton MB (1988) Evaluation of assay conditions for the zona-free hamster ova bioassay of boar sperm fertility Gamete Research 19 101-111

Berger T and Parker K (1989) Modification of the zona-free hamster ova bioassay of boar sperm fertility and correlation with in vivo fertility Gamete Research 22 385-397

Berger T, Marrs RP and Moyer DL (1985) Comparison of techniques for selection of motile spermatozoa Fertility and Sterility $43268-273$

Bryan JHD and Akruk SR (1977) A Napthol Yellow S and Erythrosin B staining procedure for use in studies of the acrosome reaction of rabbit spermatozoa Stain Technology 52 47-51

Chan SYW and Tucker MJ (1992) Differential sperm performance as judged by the zona-free hamster egg penetration test relative to differing sperm penetration techniques Human Reproduction 7 255-260

Chang MC (1957) A detrimental effect of seminal plasma on the fertilizing capacity of sperm Nature $179258-259$ 
Cheng WTK (1985) In vitro fertilisation of farm animal oocytes. PhD Thesis, Agricultural and Food Research Council, Cambridge

Cheng WTK, Polge $C$ and Moor RM (1986) In vitro fertilisation of pig and sheep oocytes Theriogenology 25146 (Abstract)

de Curtis I, Fumagalli G and Borgese N (1986) Purification and characterisation of two plasma membrane domains from ejaculated bull spermatozoa Journal of Cell Biology 102 1813-1825

Englert $\mathrm{Y}$, Van den Bergh M, Rodesch C, Bertrand E, Biramane J and Legreve A (1992) Comparative auto-controlled study between swim-up and Percoll preparation of fresh semen samples for in vitro fertilisation Human Reproduction 7 399-402

Fenichel P, Basteris B, Donzeau M, Ayraud N, Farahifar, D and Hsi BL (1991) Dynamics of human sperm acrosome reaction: relation with in vitro fertilization Fertility and Sterility 55 994-999

Forster MS, Smith WD, Lee WI, Berger RE, Karp LE and Stenchever MA (1983) Selection of human spermatozoa according to their relative motility and their interaction with zona-free hamster oocytes Ferlility and Sterility $\mathbf{4 0}$ $655-660$

Fraser LR (1984) Mechanisms controlling mammalian fertilization Oxford Reviews of Reproductive Biology 6 174-225

Gellert-Mortimer ST, Clarke GN, Gordon Baker HW, Hyne RV and Johnston WIH (1988) Evaluation of Nycodenz and Percoll density gradients for the selection of motile spermatozoa Fertility and Sterility 49 334-341

Gorus FK and Pipeleers DG (1981) A rapid method for the fractionation of human spermatozoa according to their progressive motility Fertility and Sterility 35 662-665

Guerin JF, Mathieu C, Lornage J, Pinatel MC and Boulieu, D (1989) Improvement of survival and fertilising capacity of human spermatozoa tested in an in vitro fertilisation program, by selection on discontinuous Percoll gradients Human Reproduction 4 798-804

Hunter RHF (1973) Polyspermic fertilisation in pigs after tubal deposition of excessive numbers of spermatozoa Journal of Experimental Zoology 183 $57-64$

Hunter RHF (1976) Sperm-egg interactions in the pig: monospermy, extensive polyspermy, and the formation of chromatin aggregates Journal of Anatomy $12243-59$

Hunter RHF (1990) Fertilisation of pig eggs in vivo and in vitro Joumal of Reproduction and Fertility Supplement $\mathbf{4 0} 211-226$

Hyne RV, Stojanoff A, Clarke GN, Lopata A and Johnston WIH (1986) Pregnancy from in vitro fertilisation of human eggs after separation of motile spermatozoa by density gradient centrifugation Fertility and Sterility 45 93-96

Iritani A, Niwa K and Imai $\mathbf{H}$ (1978) Sperm penetration in vivo of pig follicular oocytes matured in culture Journal of Reproduction and Fertility 54 379-383

Jeng H, Liu KM and Chang WC (1993) Purification and characterization of reversible sperm motility inhibitors from porcine seminal plasma Biochemical and Biophysical Research Communications 191 435-440

Kaneko S, Yamaguchi J, Kobayashi T and Iizuka R (1983) Separation of human Xand Y-bearing sperm using Percoll density gradient centrifugation Fertility and Sterility $4066 \mathrm{I}-665$

Kaneko S, Oshio S, Kobanawa K, Kobayashi T, Mohri H and lizuka R (1986) Purification of human sperm by a discontinuous Percoll density gradient with an inner column Biology of Reproduction 35 1059-1063

Kaneko S, Sato H, Kobanawa K, Oshio S, Kobayashi T and lizuka R (1987) Continuous-step density gradient centrifugation for the selective concentration of progressively motile sperm for insemination with husband's semen Archives of Andrology 19 75-84
Kikuchi K, Nagai T, Motlik J, Shioya Y and Izaike Y (1993) Effect of follicle cells on in vitro fertilisation of pig follicular oocytes Theriogenology 39 593-599

Le Lannou D and Blanchard Y (1988) Nuclear maturity and morphology of human spermatozoa selected by Percoll density gradient centrifugation or swim-up procedure Journal of Reproduction and Fertility 84 551-556

Lessley BA and Garner DL (1983) Isolation of motile spermatozoa by density gradient centrifugation in Percoll Gamete Research 7 49-61

McClure RD, Nunes L and Tom R (1989) Semen manipulation: improved sperm recovery and function with a two-iayer Percoll gradient Fertility and Sterility 51 874-877

Mattioli M, Bacci ML, Galeati G and Seren E (1989) Developmental competence of pig oocytes matured and fertilised in vitro Theriogenology 31 1201-1207

Mermillod P, Wils C, Massip A and Dessy F (1992) Collection of oocytes and production of blastocysts in vitro from individual, slaughtered cows Journal of Reproduction and Fertility 96 717-723

Nagai T, Niwa K, Iritani A and Leidl W (1983) Improved rates of sperm penetration in vitro of pig follicular oocytes matured in culture Japanese Journal of Fertility and Sterility 28 313-318

Nagai T, Takahashi T, Shioya $Y$ and Oguri N (1990) Maturation and fertilisation of pig follicular oocytes cultured in pig amniotic fluid Theriogenology 34 195-204

Nice L, Ray B, Grant S, Williams J, McDermott A and Hull MGR (1991) Use of Percoll in IVF: a comparison of sperm dysfunction and tubal patients Joumal of Reproduction and Fertility Abstract Series 7 Abstract 48

Rath D (1992) Experiments to improve in vitro fertilization techniques for in vivo-matured porcine oocytes Theriogenology 37 885-896

Suttiyotin P and Thwaites CJ (1992) A comparison of a swim-up technique with the Hamilton Thorne Motility analyser for measurement of sperm velocity and motility Reproduction, Fertility and Development 4 153-160

Tanphaichitr N, Millette CF, Agulnick A and Fitzgerald LM (1988) Eggpenetration ability and structural properties of human sperm prepared by Percoll-gradient centrifugation Gamete Research 20 67-81

Tuli RK, Schmidt-Baulain R and Holtz W (1992) Computer-assisted motility assessment of spermatozoa from fresh and frozen-thawed semen of the bull, boar and goat Theriogenology 38 487-490

Van der Zwalmen P, Bertin-Segal G, Geerts L, Debauche C and Schoysman R (1991) Sperm morphology and IVF pregnancy rate: comparison between Percoll gradient centrifugation and swim-up procedures Human Reproduction $6581-588$

Wang WH, Niwa K and Okuda K (1991) In-vitro penetration of pig oocytes matured in culture by frozen-thawed ejaculated spermatozoa Journal of Reproduction and Fertility 93 491-496

Wu GM, Qin PC, Tan JH and Wang LA (1992) In vitro fertilization of in vitro matured pig oocytes Theriogenology 37323

Yoshida M (1987) In vitro fertilization of pig oocytes matured in vivo Japanese Journal of Veterinary Science 49 711-718

Yoshida M, Ishizaki Y and Kawagish H (1990) Blastocyst formation by pig embryos resulting from in-vitro fertilization of oocytes matured in vitro Joumal of Reproduction and Fertility 88 1-8

Zhu YD, Piao PI, Meng WZ, Jin ZQ, Huang SH, Gao CH and Deng YH (1992) in vitro fertilisation in pigs Proceedings of 12 th Intemational Congress on Animal Reproduction 2 680-682 